\title{
The effect of genotype on a barley scutella culture. Histological aspects.
}

\section{Communication}

Halina Ślesak ${ }^{1 \star *}$, Grzegorz Góralski , Helena Pawłowska², Barbara Skucińska², Marzena Popielarska-Konieczna' ${ }^{1}$, Andrzej J. Joachimiak'

${ }^{1}$ Department of Plant Cytology and Embryology, Jagiellonian University, 31-044 Cracow, Poland

${ }^{2}$ Department of Plant Breeding and Seed Science, Agricultural University, 31-140 Cracow, Poland

Received 13 July 2012; Accepted 04 October 2012

Abstract: Cereals are known to be recalcitrant to the induction of morphogenesis in vitro and the majority of the methods used are callus-mediated and species/genotype-dependent. In the present investigation, a method of morphogenesis induction from immature scutella of selected barley cultivars was used, and particular attention was paid to histology in the initial stages of the regeneration process in order to confirm whether it occurs directly or indirectly (via callus formation). The length of the period from inoculating scutella on the medium to obtaining plantlets depended on the cultivar and the individual scutellum of the barley and varied between 2.5-4 months. The regeneration efficiency and viability of barley scutella was revealed to be highly genotype dependent. The average number of regenerated plants per regenerating scutellum was highest in the case of cv Granal (3.7). A histological analysis of the cultured explants showed both non-morphogenic and morphogenic callus formation. Two types of indirect morphogenetic response were observed: organogenesis (shoot bud formation) and somatic embryogenesis. This is the first report concerning an analysis of in vitro regeneration from immature scutella of barley cultivars (Stratus, Ryton, Granal and Binal).

Keywords: Micropropagation • Organogenesis • Somatic embryogenesis • Hordeum vulgare • Plant tissue culture

(c) Versita Sp. z 0.0 .

\section{Abbreviations:}

BAP - 6-benzylaminopurine;

2.4-D -2.4-dichlorophenoxyacetic acid;

PAA - phenylacetic acid;

TDZ - thidiazuron.

\section{Introduction}

In order to improve crop plants using biotechnological methods, we need micropropagation techniques that deliver efficient long-term plant regeneration from a small number of cells that can be altered through transformation, mutation or fusion. Micropropagation is also useful for the multiplication of valuable plants and for maintaining collections or pathogen-free lines.
For all these purposes an efficient procedure that does not produce additional variation is needed. Such a procedure should be based on direct morphogenesis, since indirect regeneration via the callus may cause many problems due to the somaclonal variability of this tissue [1].

Cereals, especially those planted in temperate zones, are known to be recalcitrant to the induction of morphogenesis in vitro [2,3]. The majority of methods for their micropropagation are callus-mediated and genotype-dependent. Studies have shown in vitro regeneration from shoot apices [4-6], meristematic segments of young seedlings [7-9] and leaf bases [10]. Some authors have reported the regeneration of adventitious shoots from enlarged shoot apical meristems without a callus phase [3-7] or with only a minimal callus phase [9]. 
Efficient regeneration is usually observed on calli that originated from embryos or their parts [7,11-16]. Histological studies have identified the scutellum of an immature embryo as the tissue from which embryogenic calli originate [17-20]. Few studies, however, have examined the anatomy of somatic embryogenesis and the ontogeny of somatic embryos obtained from scutella [1,11,21-23].

Eudes et al. [1] described the induction of direct somatic embryogenesis from scutella in seven species of cereals, including barley. They stated that none of the plants that had been regenerated in their laboratory showed visible somatic variation, albinism or loss of fertility and that the repeatability and efficiency of this method was high. Although this method seems very promising, its broad applicability needs to be confirmed, especially for barley, which is known to be the most recalcitrant to tissue culture among the major cereals [3]. The majority of studies on its cultivars have been conducted to develop an effective protocol for the induction of an embryogenic callus and to increase the frequency of plant regeneration from this tissue [24-26]. All Polish varieties of barley tested to date were regenerated via the callus and analyzed using this approach [27].

In this study, we applied the regeneration system described by Eudes et al. [1] to selected cultivars of barley, in order to track the course of the morphogenetic response and to answer the questions: 1 ) Is it possible to obtain direct organogenesis or somatic embryogenesis from immature scutella in the genotypes analyzed? 2) What is the effect of genotype on morphogenesis in this micropropagation system?

\section{Experimental Procedures}

\subsection{Tissue culture}

The Polish cultivars of spring barley, Stratus, Ryton, Granal and Binal, that were used in this experiment were obtained from breeders. Donor plants were sown in an experimental field. Immature spikes were harvested approx. 14 days after anthesis, when embryo size reached $1.5-2 \mathrm{~mm}$. The spikes were wrapped in foil and stored at $4^{\circ} \mathrm{C}$ for $3-7$ days for cold pretreatment and then immature caryopses were excised. After washing in running water, the caryopses were sterilized in $70 \%$ ethanol for $30 \mathrm{~s}$, rinsed in sterile distilled water, shaken on a stirrer for $5 \mathrm{~min}$ and immersed in Domestos commercial bleach diluted down to $2 \%$ sodium hypochlorite for $15 \mathrm{~min}$. Then they were rinsed in double-distilled and sterilized water five times for $5 \mathrm{~min}$. Embryo scutella were aseptically isolated with forceps and a scalpel under a stereomicroscope.

The culture protocol was based on Eudes et al. [1]. The culture was divided into five phases: (a) induction of somatic embryogenesis and/or organogenesis, (b) secondary embryogenesis, (c) growth of embryos, (d) regeneration of shoots and (e) rooting, each in a specific culture medium. The media, especially those used in the first three phases of the culture, contained salts, 5 carbohydrates, 18 amino acids, 10 vitamins, 6 organic acids and 5 plant growth regulators (including spermine and spermidine). They were solidified with Gelrite (Duchefa Biochemie, Haarlem, The Netherlands) except for the rooting medium, which was solidified with agar.

\subsection{Statistical analysis}

For each barley cultivar, between 69 and 99 scutella were isolated (356 in total). Each experiment was repeated three or four times with 23-30 explants from each cultivar each time. In order to assess the effect of genotype on regeneration, Pearson's chi-squared test was used with two-dimensional contingency tables to compare the numbers of dead and regenerated scutella for each genotype.

An exact binomial test was used to calculate the confidence intervals to compare the viability of scutella in different culture phases. Calculations and charts were done in the $\mathrm{R}$ statistical environment ( $\mathrm{R}$ Core Team. $\mathrm{R}$ Foundation for Statistical Computing, Vienna, 2012, http://www.R-project.org/).

\subsection{Histological analyses}

Histological analyses were performed on explants collected after 7-16 days of culture. The material was prepared for embedding tissues in Technovit 7100 (2-hydroxyethylmethacrylate) (Heraeus Kulzer $\mathrm{GmbH}$, Wehrheim, Germany). Explants were fixed in $25 \%$ glutaraldehyde for $24 \mathrm{~h}$, washed four times in a $0.1 \mathrm{M}$ phosphate buffer (PBS) followed by dehydration in a graded ethanol series $(10 \%, 30 \%, 50 \%, 70 \%, 96 \%)$ for $15 \mathrm{~min}$ at each concentration and kept overnight in absolute ethanol. Later, the samples were infiltrated in a mixture of absolute ethanol and Technovit ( $1 \mathrm{~h}$ at each proportion: $3: 1,1: 1,1: 3 ; \mathrm{v} / \mathrm{v}$ ) and stored for $12 \mathrm{~h}$ in pure Technovit. The resin was polymerized with the addition of hardener. The material was sectioned to $5 \mu \mathrm{m}$ with a rotary microtome (Microm, Adamas Instrumenten), stained with $0.1 \%$ toluidine blue $\mathrm{O}$ (TBO) and mounted in Entellan synthetic resin (Merck, Darmstadt, Germany).

Microscopic sections were photographed using a Zeiss AxioCam MRe digital camera with Zeiss Axio Vision 3.0 software. 


\section{Results}

\subsection{Tissue culture}

The culture period necessary to obtain plantlets from inoculating the scutella on a medium depended on the cultivar and the individual scutellum and lasted from 2.5 to 4 months. Statistical analysis (chi-square tests) indicate that regeneration efficiency was highly genotype-dependent (Figure 1). The highest number of scutella with regeneration potential (33.7\%) (Figure 1) and the highest average number of regenerated plants per regenerating scutellum (3.7) (Table 1) was obtained in the case of cv. Granal. Statistical analysis revealed that the viability of barley scutella was also strictly genotype-dependent. The highest viability during the subsequent culture phases was noted in cv. Granal (Figure 2).

\subsection{Morphological observations}

After seven days of culture initiation, the induction of soft, friable and translucent callus on barley explants was observed (Figure 3a). Later, the callus structure changed and two callus types were clearly recognized: a soft, friable, translucent non-embryogenic callus and a nodular, smooth, compact embryogenic callus. Between 11 and 16 days after the initiation of a culture, embryolike structures and somatic embryos at different stages of development were observed on the callus surface (Figure 3b-d). Clusters of somatic embryos were also noted in the cv. Ryton explants (Figure 3e,f).

Somatic embryogenesis was accompanied by organogenesis, in which shoots formed and developed reduced leaf primordia in two cultivars (Stratus, Granal) (Figure 3g). Rhizogenesis was induced only in explants of the cv. Granal barley (Figure 3h).

\subsection{Histological analyses}

Indirect (via callus) somatic embryogenesis and organogenesis was observed on analyzed scutella of the three barley cultivars analysed with the highest regeneration ability (Granal, Ryton, Stratus). Cross

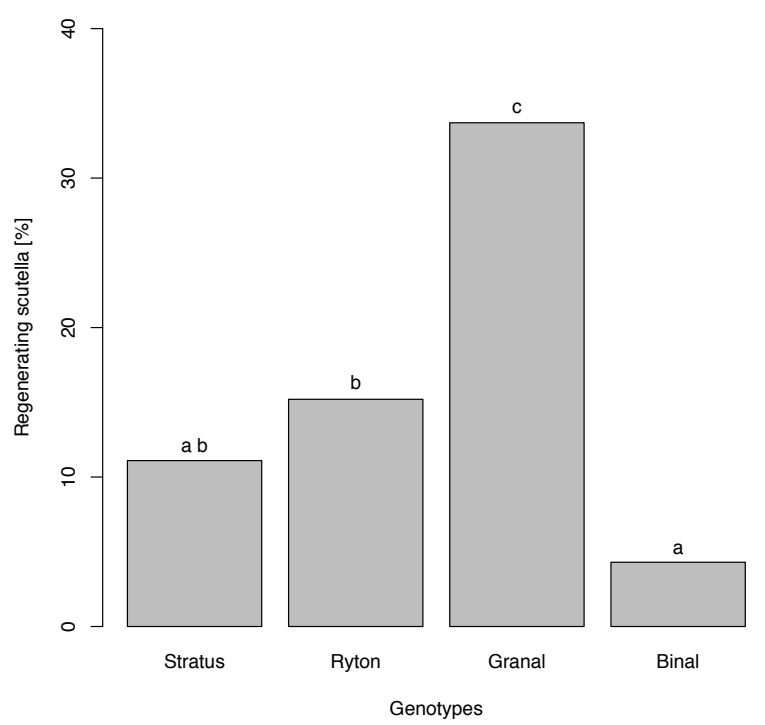

Figure 1. The effect of genotype on regeneration from barley scutella. The same letters above the bars indicate no significant differences between means, at least at the level of $P<0,05$.
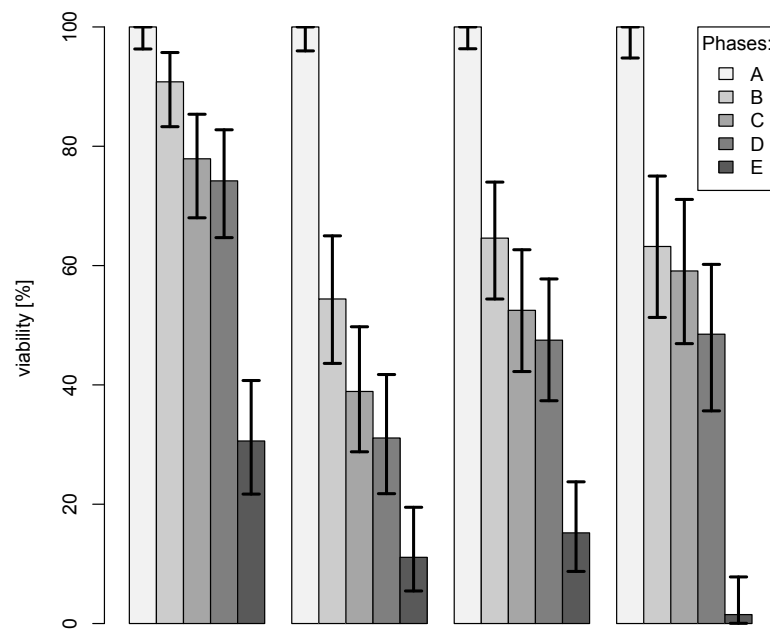

Granal

Ryton

Binal

Figure 2. Viability [\%] of scutella in barley cv. Granal, Stratus, Ryton and Binal during in vitro culture phases. A - induction of somatic embryogenesis and organogenesis; $\mathrm{B}$ - secondary embryogenesis; $\mathrm{C}$ - growth of embryos; $\mathrm{D}$ - regeneration of shoots; $\mathrm{E}$ - rooting. Bars indicate $95 \%$ confidence intervals.

\begin{tabular}{c|cccc}
\hline \multirow{2}{*}{ Cultivar } & No. of plated scutella & Regenerating scutella & \multicolumn{2}{c}{ Average number of regenerated plants } \\
& & & per plated scutellum & per regenerating scutellum \\
\hline \hline Stratus & $90(3)$ * & 10 & 0.3 & 2.7 \\
Ryton & $99(4)$ & 15 & 0.2 & 1.5 \\
Granal & $98(4)$ & 33 & 1.2 & 0.1 \\
Binal & $69(3)$ & 3 & 1.0 \\
\hline
\end{tabular}

Table 1. Efficiency of plant regeneration from scutella explants of barley cultivars 

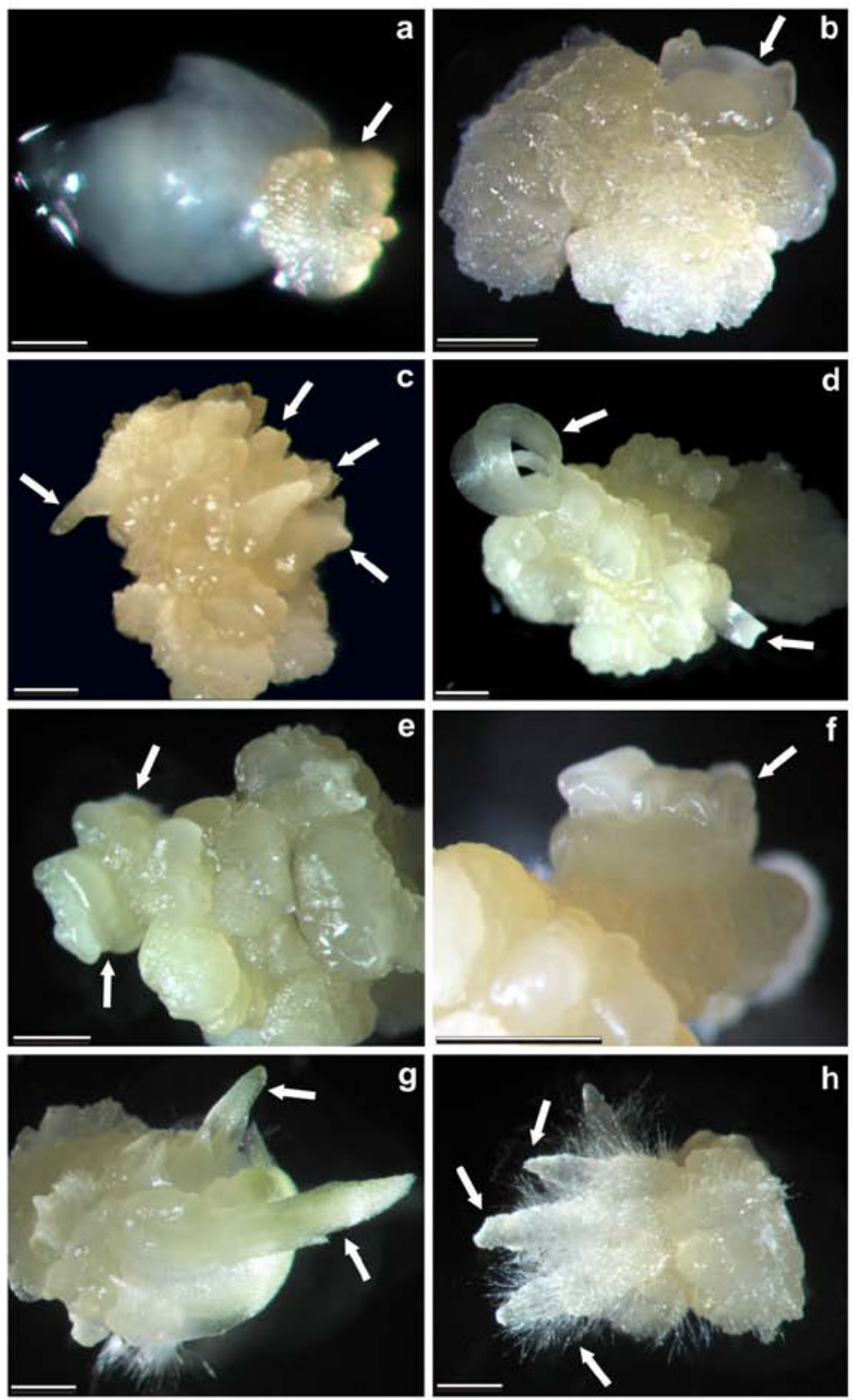

Figure 3. Scutella explants of barley. a) cv. Granal, callus formation on the peripheral region of the scutellum (arrow), 7 days after culture initiation. b) cv. Granal, embryo-like structure on the callus surface (arrow), 14 days after culture initiation. c) cv. Stratus, somatic embryos (arrows), 11 days after culture initiation. d) cv. Ryton, somatic embryos with a cotyledonary leaf (arrows), 16 days after culture initiation. e, f) cv. Ryton, clusters of somatic embryos (arrows), 16 days after culture initiation. g) cv. Stratus, visible shoots with reduced leaf primordia (arrows), 11 days after culture initiation. h) cv. Granal, roots (arrows), 14 days after culture initiation (bars $=1 \mathrm{~mm}$ in a-h).

sections of a 7-day-old scutellum (i.e., after 7 days of culture) of cv. Granal revealed an enlargement of the scutellar surface that appeared to be bumpy. A soft, unorganized and translucent callus emerged from the peripheral region of the scutellum (Figure 4a). Two types of callus were formed: (1) a non-embryogenic callus, which was soft, friable, translucent and consisted of elongated and vacuolated cells and (2) an embryogenic callus, which was nodular, smooth, compact and composed of small, dense, slightly vacuolated cells.

Cross sections through the embryogenic callus showed globular somatic embryos or embryo-like structures originating either from the cells inside the callus (Figure 4b) or from the callus surface (Figure 4c,d). Typical-looking somatic embryos were infrequent (Figure 4e); most commonly, embryo-like structures or groups of fused somatic embryos were formed (Figure 4f). 


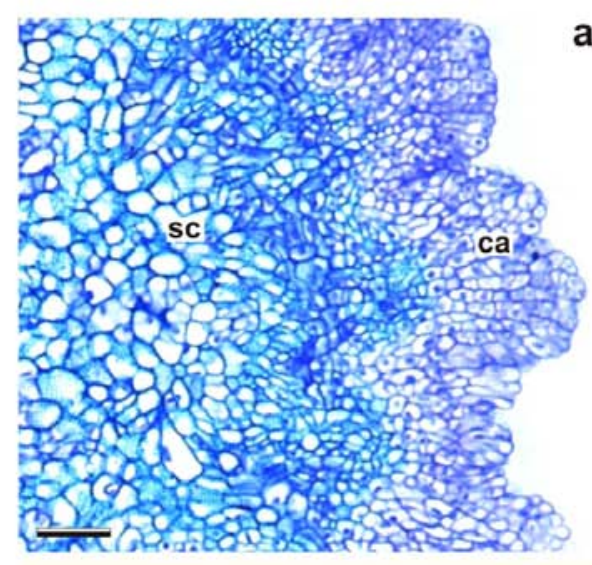

a
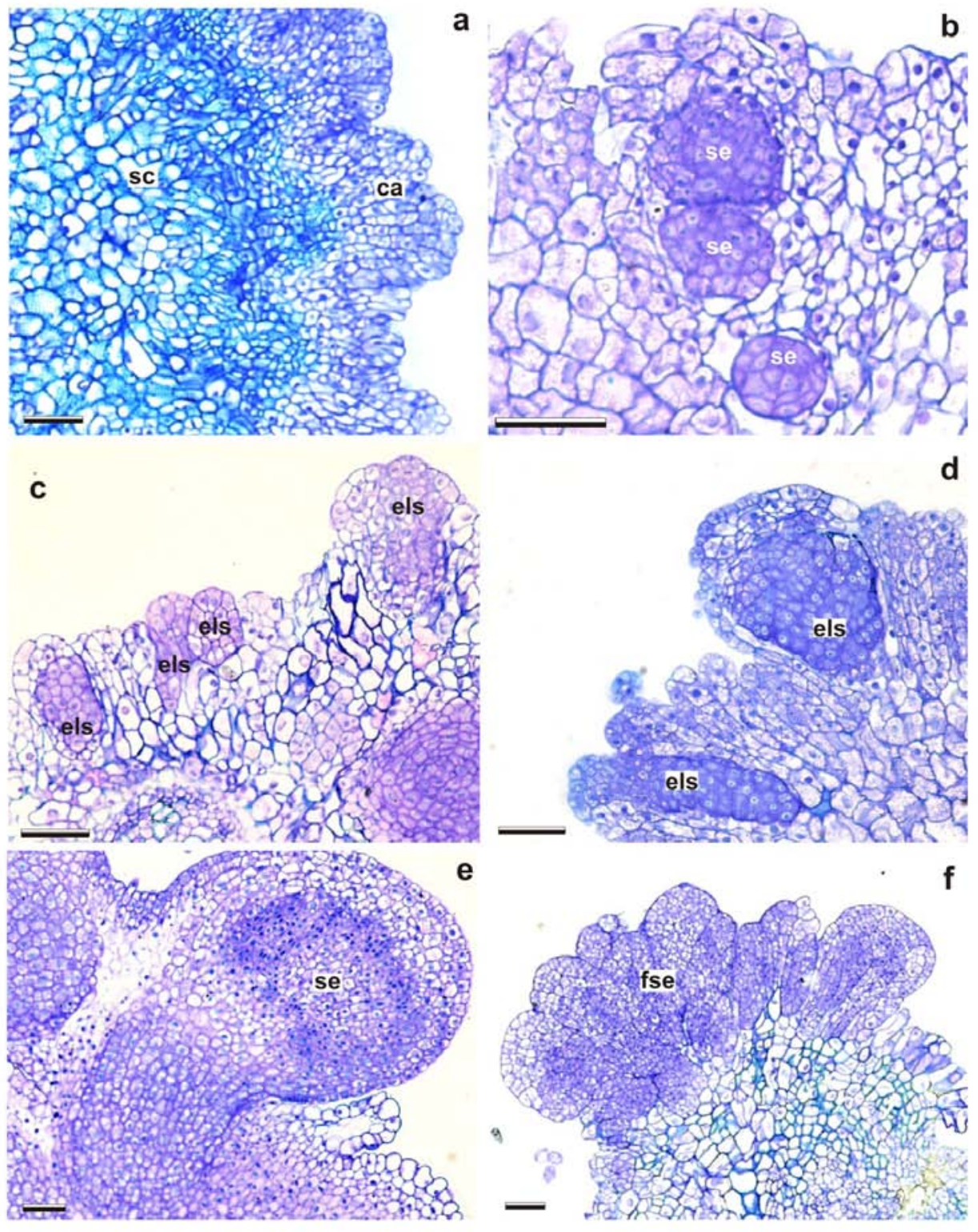

Figure 4. Histological cross sections of the cultured scutella of barley. a) cv. Granal, 7 days of culture, callus (ca) formation on the peripheral region of the scutellum (sc). b) cv. Ryton, 9 days of culture, somatic embryos (se) initiated within the callus. c) cv. Granal, 14 days of culture, embryo-like structures (els) on the callus surface. d) cv. Ryton, 9 days of culture, embryo-like structures (els) on the callus surface. e) cv. Stratus, 11 days of culture, a somatic embryo (se). f) cv. Ryton, 9 days of culture, a group of fused somatic embryos (fse) (bars = $100 \mu \mathrm{m}$ in $\mathrm{a}-\mathrm{f})$

Regeneration via organogenesis was observed at the same time. Root formation on the cv. Granal explants was visible macroscopically. Histological sections showed that the roots probably originated directly from the scutella (Figure $5 a$ ), whereas the shoots originated indirectly. Root and shoot formation is presented in Figures 5a,d. Sections of 7-day-old cv. Granal explants presented compact meristematic tissue consisting of small, intensely stained isodiametric cells with a centrally located nucleus (Figure 5b). Several meristemoids developing on the surface of proliferating nodular callus were seen in the cv. Stratus barley (Figure 5c). After 11 days of culture, shoot buds with a visible shoot apical dome differentiated in the meristematic bulk tissue (Figure $5 \mathrm{~d}$ ). Frequently, there were a large number of randomly scattered tracheal elements in the callus mass (data not shown). 


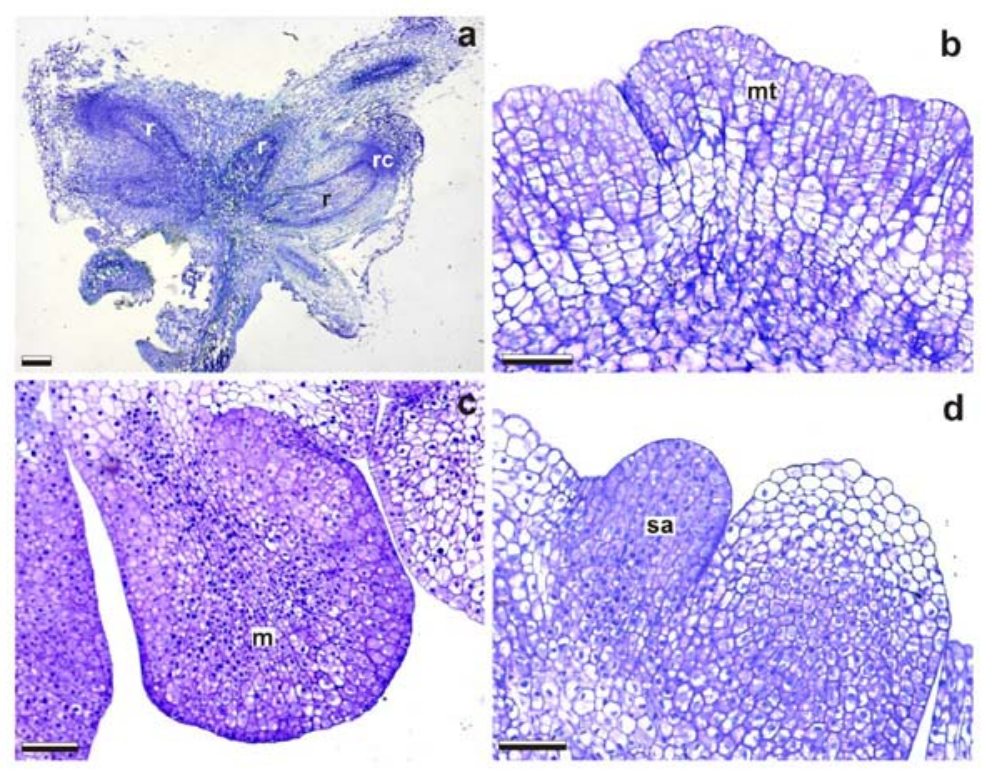

Figure 5. Histological cross sections of the cultured scutella of barley. a) cv. Granal, 14 days of culture, visible roots (r) with a root cap (rc). b) cv. Granal, 7 days of culture, formation of compact meristematic tissue (mt). c) cv. Stratus, 11 days of culture, meristemoids $(\mathrm{m})$ on the callus surface. d) cv. Stratus, 11 days of culture, visible shoot apical meristematic tissue (sa) (bars $=100 \mu \mathrm{m}$ in a-d)

\section{Discussion}

Obtaining transgenic plants from cultivars of agronomic value requires not only a reliable method of transferring genes into cells but also an efficient micropropagation procedure that does not cause additional variation [6]. Eudes et al. [1] described a procedure for direct somatic embryogenesis in several species of cereals. When comparing their results for barley with our observations, we noted that the period from the initiation of a culture to the regeneration phase was similar, as was the percentage of scutella that regenerated plants. The differences lay mainly in the efficiency of the method, which in our material was markedly lower and was genotype-dependent.

Using the media and culture procedures they described [1], we did not observe direct somatic embryogenesis in the analyzed barley cultivars. Histological analysis of the cultured explants made it clear that somatic embryogenesis was preceded by the formation of callus tissue. Two types of callus proliferated: compact embryogenic and friable nonembryogenic. Other authors have reported similar results [25-28].

We most often observed embryo-like structures or groups of somatic embryos that had probably originated from fused sites of a somatic embryo origin, as Nonohay et al. [23] reported in $H$. vulgare. Oka et al. [18] described comparable "globular" or "embryo-like" bipolar structures and noted that typical somatic embryos with a distinct scutellum, shoot apex and radicle were very seldom formed.
Our histological sections also showed a differentiation of roots, leafy structures and shoot buds, which is similar to the observations of Weigel and Hughes [29]. Oka et al. [18] reported that a barley scutellum-derived callus gave rise to a number of roots without shoots. We observed only a few cases of this phenomenon (e.g., in cv. Granal).

The procedure described by Eudes et al. [1] differs from other procedures in its use of a sequence of five media, among which the three media inducing embryogenesis and embryo germination are exceptionally rich in organic components. Apart from the growth regulators commonly used in tissue culture (2,4-D, PAA, BAP), the media contain polyamines, which have been found to act as growth stimulants and to enhance the action of plant growth substances. The results obtained by Eudes et al. [1] presumably were determined by both the composition and sequence of the media. They stated that in barley and wheat, species that have many genotypes, the procedure has the advantage of being genotype-independent, but in our experiment their media failed to produce similar effects. Regeneration of cereals still runs into the problem of a genotype-dependent response [30]. According to León et al. [31], the better response of some genotypes (also within spikes of the same genotype) may be due to the level of endogenous phytohormones. Other factors such as donor plant quality may also affect the results of culture [32,33].

The laborious protocol used in this experiment did not yield a high performance or direct embryogenesis 
in the plants analyzed. The number of regenerated plants per regenerating scutellum (1.0-3.7) was lower than that reported by Eudes et al. [1] and by authors testing other regeneration methods [24-27]. Note that most of the cited works examined different, mostly local varieties. Among the four barley cultivars we studied in our experiment, we have satisfactory comparative data only for $\mathrm{cv}$. Stratus, whose regeneration from the apical meristems of seedlings was examined previously [34] using three different regeneration methods from Zhang et al. [4], Sharma et al. [8] and Ganeshan et al. [3]. In this case as well, the protocol we tested proved less efficient. This outcome casts doubt on the likelihood that it will ever be possible to develop a single satisfactory method of micropropagation for different barley lines and confirms the suggestion [3] that the culture media for tissue cultures of such difficult material need to be modified for specific varieties.

\section{References}

[1] Eudes F., Acharya S., Laroche A., Selinger L.B., Cheng K., A novel method to induce direct somatic embryogenesis, secondary embryogenesis and regeneration of fertile green cereal plants, Plant Cell Tissue Organ Cult., 2003, 73, 147-157

[2] Vasil I.K., The story of transgenic cereals: the challenge, the debate and the solution-a historical perspective, In Vitro Cell. Dev. Biol. - Plant, 2005, 41, 577-583

[3] Ganeshan S., Chodaparambi S.V., Båga M., Fowler D.B., Hucl P., Rossnagel B.G., et al., In vitro regeneration of cereals based on multiple shoot induction from mature embryos in response to thidiazuron, Plant Cell Tissue Organ Cult., 2006, 85, 63-73

[4] Zhang S., Zhong H., Sticklen M.B., Production of multiple shoots from shoot apical meristems of oat (Avena sativa L.), J. Plant Physiol., 1996, 148, 667-671

[5] Zhang S., Williams-Carrier R., Jackson D., Lemaux P.G., Expression of CDC2Zm and KNOTTED1 during in vitro axillary shoot meristem proliferation and adventitious shoot meristem formation in maize (Zea mays L.) and barley (Hordeum vulgare L.), Planta, 1998, 204, 542-549

[6] Zhang S., Cho M.J., Koprek T., Yun R., Bregitzer P., Lemaux P.G., Genetic transformation of commercial cultivars of oat (Avena sativa L.) and barley (Hordeum vulgare L.) using in vitro shoot meristematic cultures derived from germinated seedlings, Plant Cell Rep., 1999, 18, 959-966
In conclusion, the in vitro regeneration process in several barley cultivars (Stratus, Ryton, Granal, Binal) was analysed in this study, and particular attention was paid to histology in the initial stages in order to confirm whether it occurs with or without callus formation. A histological analysis of the cultured explants made it clear that the somatic embryogenesis that was observed was preceded by the formation of callus tissue. This is the first report concerning the analysis of in vitro regeneration from the immature scutella of barley cultivars (Stratus, Ryton, Granal and Binal).

Although the culture procedure for direct somatic embryogenesis described by Eudes et al. [1] seems to be very promising, and as the authors claimed, has the advantage of being genotype independent, the results described in this paper show that its broad applicability in cereals needs to be verified.

[7] Ganeshan S., Båga M., Harvey B.L., Rossnagel B.G., Scoles G.J., Chibbar R.N., Production of multiple shoots from thidiazuron-treated mature embryos and leaf-base /apical meristems of barley (Hordeum vulgare), Plant Cell Tissue Organ Cult., 2003, 73, 57-64

[8] Sharma V.K., Hänsch R., Mendel R.R., Schulze J., A highly efficient plant regeneration system through multiple shoot differentiation from commercial cultivars of barley (Hordeum vulgare L.) using meristematic shoot segments excised from germinated mature embryos, Plant Cell Rep., 2004, 23, 9-16

[9] Sharma V.K., Hänsch R., Mendel R.R., Schulze J., Influence of picloram and thidiazuron on high frequency plant regeneration in elite cultivars of wheat with long-term retention of morphogenicity using meristematic shoot segments, Plant Breed., 2005, 124, 242-246

[10] Li H.P., Huang T., Wang C.X., Liao Y.C., An efficient regeneration system of barley cultivars from leaf base segments, Biol. Plant., 2009, 53, 733-736

[11] Kachhwaha S., Varshney A., Kothari S.L., Somatic embryogenesis and long term high plant regeneration from barley (Hordeum vulgare L.) using picloram, Cereal Res. Commun., 1997, 2, 117-123

[12] Kelley R.Y., Zipf A.E., Wesenberg D.E., Sharma G.C., Comparative evaluation of three tissue culture methods for the improvement of plant regeneration from diverse oat (Avena ssp. L.) genotypes, Cereal Res. Commun., 2004, 1, 113-118 
[13] Satyavathi V.V., Jauhar P.P., Elias E.M., Rao M.B., Effects of growth regulators on in vitro plant regeneration in durum wheat, Crop Sci., 2004, 44, 839-1846

[14] Sharma V.K., Hänsch R., Mendel R.R., Schulze J., Mature embryo axis-based high frequency somatic embryogenesis and plant regeneration from multiple cultivars of barley (Hordeum vulgare L.), J. Exp. Bot., 2005, 417, 1913-1922

[15] Filippov M., Miroshnichenko D., Vernikovskaya D., Dolgov S., The effect of auxins, time exposure to auxin and genotypes on somatic embryogenesis from mature embryos of wheat, Plant Cell Tissue Organ Cult., 2006, 84, 213-222

[16] Jha A.K., Dahleen L.S., Suttle J.C., Ethylene influences green plant regeneration from barley callus, Plant Cell Rep., 2007, 26, 285-290

[17] Dunstan D.I., Short K.C., Thomas E., The anatomy of secondary morphogenesis in cultured scutellum tissues of Sorghum bicolour, Protoplasma, 1978, 97, 251-260

[18] Oka S., Saito N., Kawaguchi H., Histological observations on initiation and morphogenesis in immature and mature embryo derived callus of barley (Hordeum vulgare L.), Ann. Bot., 1995, 76, 487-492

[19] Deepinder G., Raman G., Gosal S.S., Factors enhancing induction of high frequency plant regeneration from somatic embryos of indica rice (Oryza sativa L.), Int. J. Biol. Sci., 2005, 5, 697-702

[20] Sharma V.K., Hänsch R., Mendel R.R., Schulze J., Seasonal effect on tissue culture response and plant regeneration frequency from non-bombarded and bombarded immature scutella of barley (Hordeum vulgare) harvested from controlled environment, Plant Cell Tissue Organ Cult., 2005, 81, 19-26

[21] Lu C., Vasil, I.K., Histology of somatic embryogenesis in Panicum maximum Jacq. (Guinea grass), Amer. J. Bot., 1985, 72, 1908-1913

[22] Fernandez S., Michaux-Ferrière N., Coumans M., The embryogenic response of immature embryo cultures of durum wheat (Triticum durum Desf.): histology and improvement by $\mathrm{Ag} \mathrm{NO}$, Plant Growth Reg., 1999, 28, 147-155

[23] Nonohay J.S., Mariath J.E.A., Winge H., Histological analysis of somatic embryogenesis in brazilian cultivars of barley, Hordeum vulgare vulgare, Poaceae, Plant Cell Rep., 1999, 18, 929-934

[24] Halàmkovà E., Vagera J., Ohnoutkovà L., Regeneration capacity of calli derived from immature embryos in spring barley cultivars, Biol. Plant., 2004, 48, 313-316

[25] Šerhantová V., Ehrenbergerová J., Ohnoutková L., Callus induction and regeneration efficiency of spring barley cultivars registered in the Czech Republic, Plant Soil Environ., 2004, 50, 456-462

[26] Tanasienko I.V., Yemets A.I., Blume Ya.B., Estimation of the callus formation and regeneration efficiency in spring varieties of barley zoned in Ukraine, Cytol. Genet., 2009, 43, 230-236

[27] Przetakiewicz A., Orczyk W., Nadolska-Orczyk A., The effect of auxin on plant regeneration of wheat, barley and triticale, Plant Cell Tissue Organ Cult., 2003, 73, 245-256

[28] Mohanty B.D., Ghosh P.D., Somatic embryogenesis and plant regeneration from leaf callus of Hordeum vulgare, Ann. Bot., 1988, 61, 551-555

[29] Weigel R.C., Hughes K.W., Long term regeneration by somatic embryogenesis in barley (Hordeum vulgare L.) tissue cultures derived from apical meristem explants, Plant Cell Tissue Organ Cult., 1985, 5, 151-162

[30] Dahleen L.S., Bregitzer P., An improved media system for high regeneration rates from barley immature embryo-derived callus cultures of commercial cultivars, Crop Sci., 2002, 42, 934-938

[31] León E., Marín S., Barro F., Improvement of in vitro culture response of elite wheat cultivars by selecting the source spike, the scutellum size and the temperature for the induction of embryogenesis, Plant Breed., 2006, 125, 580-583

[32] Jähne-Gärtner A., Lörz H., In vitro regeneration systems of barley (Hordeum vulgare L.), Plant Tissue Cult. Biotech., 1996, 12, 11-23

[33] Bartlett J.G., Alves S.C., Smedley M., Snape J.W., Harwood W.A., High-throughput Agrobacteriummediated barley transformation, Plant Meth., 2008, 4,22

[34] Kruczkowska H., Pawłowska H., Skucińska B., Comparison of micropropagation methods in Polish cultivars of barley and oat, Biotechnologia, 2008, 2, 83-88 (in Polish with English summary) 